\title{
Management of Angle Class I Malocclusion with Severe Crowding and Bimaxillary Protrusion by Extraction of Four Premolars: A Case Report
}

\author{
Putri Intan Sitasari and Ida Bagus Narmada \\ Department of Orthodontic, Faculty of Dental Medicine, Universitas Airlangga, Surabaya, Indonesia
}

\begin{abstract}
Crowding and protrusion are some of the most common dental cases worldwide. The patient was a 20-year-old female who consulted for severe crowding, protrusion, and deep bite. Clinical examination and cephalometric measurement showed Class I skeletal and proclined incisor. Two step retraction technique was used to correct the condition. Management of tooth tissue discrepancy by the extraction of four premolars is one of the options in the treatment of crowding.
\end{abstract}

Key Words: Class I Angle malocclusion, premolars extraction, crowding, orthodontic treatment

\section{INTRODUCTION}

The most common malocclusions worldwide is Angle's Class I with crowding. The dento-alveolar incongruence with crowding is frequently seen in malocclusion among the population, and has various etiology. Bimaxillary Protrusion could present in a patient as protrusive lips and convex profile. It is seen most commonly in African-American and Asian populations, but it can also be seen in almost every other ethnic group. There is negative perception of protrusive dentition and lips in most cultures, and many patients with bimaxillary protrusion seek orthodontic care to decrease this procumbency. ${ }^{1,2,3}$ The main goal of orthodontic treatment is to obtain a normal relationship of the teeth with facial structures and give the patient a better face profile. Angle emphasized that the preservation of all dental structures was necessary to achieve facial balance. However, there are soft tissue constraints that limit the amount of alteration that can be performed orthodontically, which necessitates the need for extraction. ${ }^{4}$

Due to increased consciousness regarding facial appearance, aesthetic treatment has become very common practice these days. The goals of orthodontic treatment of bimaxillary protrusion include the retraction and retroclination of maxillary and mandibular incisors which

Paper presented at the Joint Scientific Meeting in Special Care Dentistry, July 5, 2019, Amerta Room, 4th Floor, main campus of Universitas Airlangga, Surabaya, Indonesia.

Corresponding author: Ida Bagus Narmada

Department of Orthdontic

Faculty of Dental Medicine

Universitas Airlangga

Jl. Mayjen. Prof. Dr. Moestopo No. 47 Surabaya 60132 - Indonesia

Email:dr_narmada@yahoo.com result to decrease in soft tissue procumbency and convexity. ${ }^{2}$ This is most commonly achieved by the extraction of four first premolars followed by the retraction of anterior teeth using maximum anchorage mechanics. ${ }^{5}$

Choice of treatment for crowding depends on age, affected jaw, and the severity of crowding. To achieve best results, it is important to decide the management of each case of crowding. The problem may be solved by either 
extracting teeth in both arches or not extracting. The degree of the malocclusion and the number of teeth extracted affect the treatment duration. ${ }^{2}$

\section{CASE REPORT}

The patient was a 20-year-old female with chief complaint of crowding teeth and protrusive lips (Figure 1). She was concerned about her facial profile and thus her lack of confidence. The patient had no other remarkable finding in medical history and physical examination. Dental clinical examination showed severe crowding in both upper and lower arches in the anterior region. Overjet was normal $(3 \mathrm{~mm})$ and there was a little increase in overbite $(4 \mathrm{~mm})$.
As the arch-length discrepancy was present in both the maxillary arch $(10 \mathrm{~mm})$ and the mandibular arch $(8 \mathrm{~mm})$. Lower arch was square shaped. Canines and molars were in Class I relationship. Left second upper incisor was palatally positioned and in a crossbite relationship with the lower teeth thus there was an anterior crossbite between the left upper incisors and lower second left incisors (Figure 2). There were no clinical signs of clicking or discomfort in the temporomandibular joints; there was no restriction or deviation in jaw movement. No pathologic findings were detected from the panoramic radiograph. Lateral cephalometric analysis revealed a Class I skeletal relationship with $\angle \mathrm{SNA} 81^{\circ}, \angle \mathrm{SNB} 78^{\circ}, \angle \mathrm{ANB} 3^{\circ}$ (Figure 3). Dental measurement showed that upper and lower incisors were
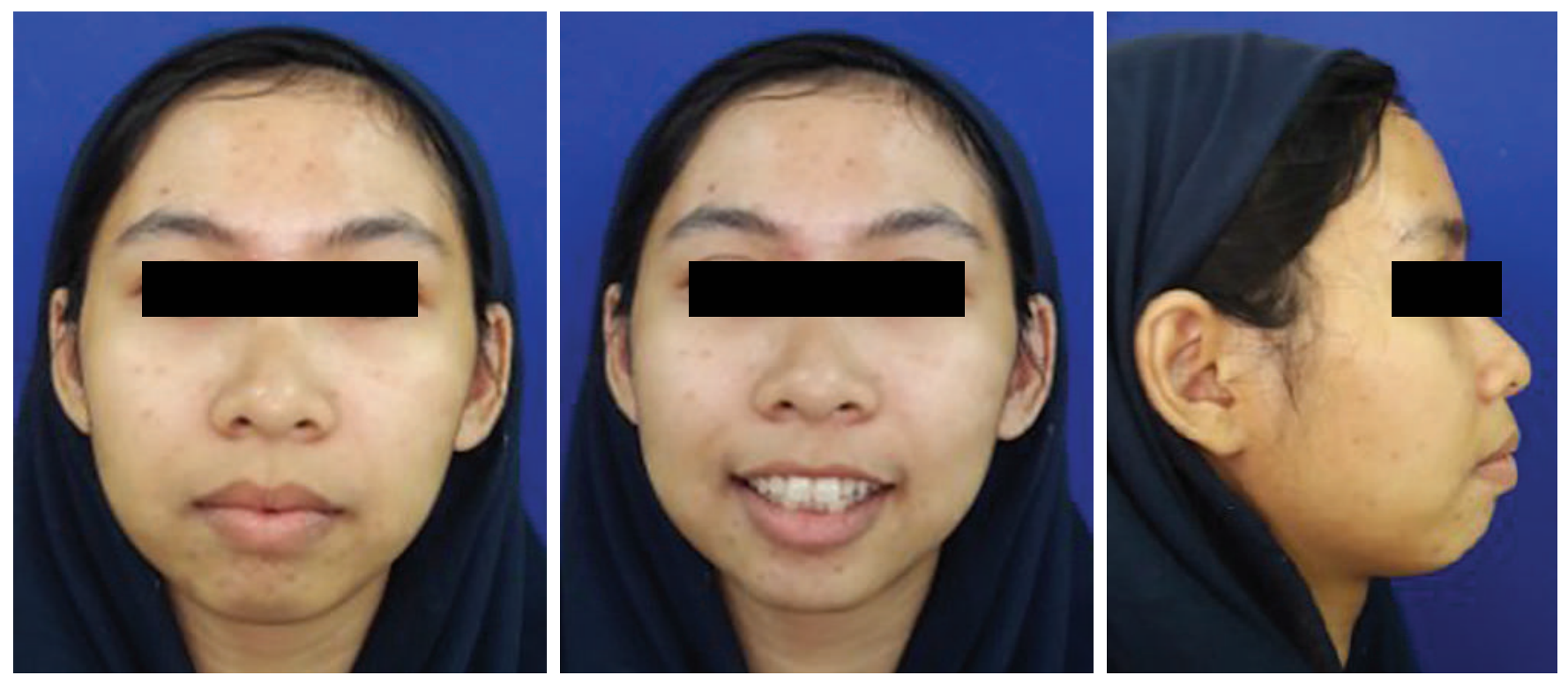

Figure 1. Pre-Treatment Extra Oral Photographs.
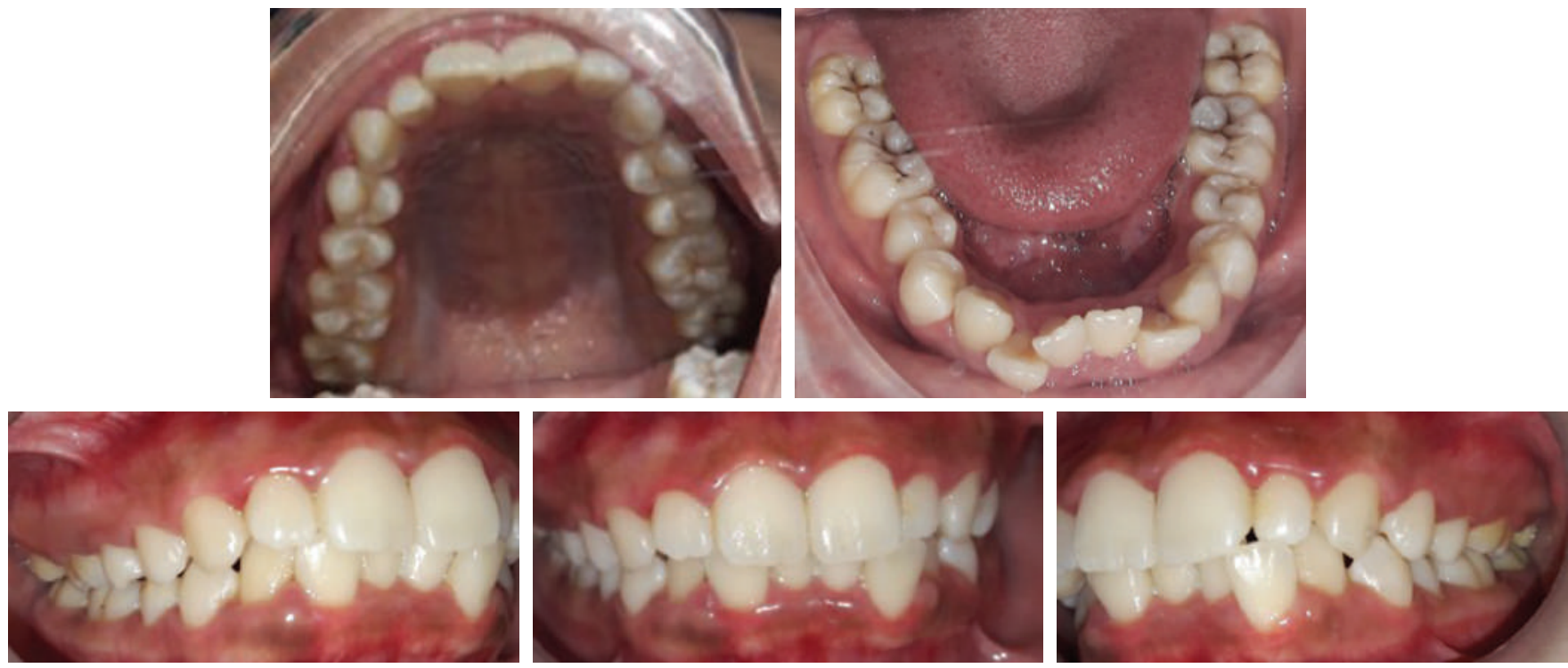

Figure 2. Pre-Treatment Intra Oral Photographs. 

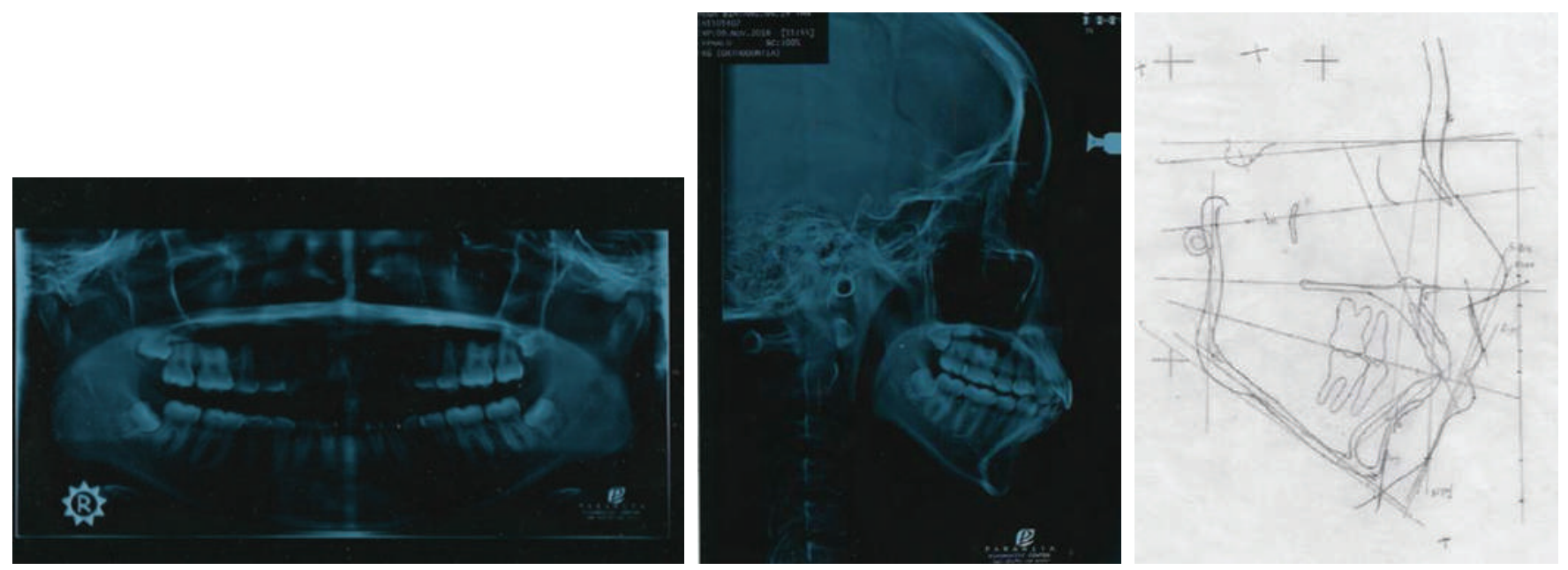

Figure 3. Pre-Treatment OPG and Cephalogram.

proclined $\angle \mathrm{I}-\mathrm{NA} 28^{\circ}, \angle \mathrm{I}-\mathrm{NB} 31^{\circ} \angle$ Inter Incisal $117^{\circ}$. Soft tissue analysis using Rickett's Lip Analysis and Steiner's Lip Analysis showed that the upper and lower lips were in front of the E-lines and S-lines which meant the patient had protrusive lips (Table 1).

Table 1. Pre- and Post-Treatment Cephalogram's Measurements

\begin{tabular}{|c|c|c|c|}
\hline \multirow{2}{*}{ Measurement } & \multirow{2}{*}{$\begin{array}{c}\text { Surabaya } \\
\text { Mean }\end{array}$} & \multicolumn{2}{|c|}{ Subject } \\
\hline & & Pre & Post \\
\hline$\angle S N A$ & 84.3 & 81 & 81 \\
\hline$\angle \mathrm{SNB}$ & 81,4 & 78 & 78 \\
\hline$\angle \mathrm{ANB}$ & 3 & 3 & 3 \\
\hline$\angle \mathrm{OP}-\mathrm{SN}$ & $15-32$ & 20 & 20 \\
\hline$\angle \mathrm{MP}-\mathrm{SN}$ & $20-40$ & 42 & 42 \\
\hline$\angle 1-N A$ & 26 & 28 & 26 \\
\hline 1-NA (mm) & 6,3 & 7 & 5 \\
\hline$\angle 1-N B$ & 29 & 31 & 28 \\
\hline $1-\mathrm{NB}(\mathrm{mm})$ & 7,9 & 8 & 6 \\
\hline Nasolabial Angle & $110-120^{\circ}$ & $97^{\circ}$ & $105^{\circ}$ \\
\hline Upper lips - E line & $-2-3 m m$ & $+4 \mathrm{~mm}$ & $+2 \mathrm{~mm}$ \\
\hline Lower lips -E line & $-1-2 m m$ & $+6 \mathrm{~mm}$ & $+4 \mathrm{~mm}$ \\
\hline Upper lips-S line & 0 & $+3 \mathrm{~mm}$ & $+1 \mathrm{~mm}$ \\
\hline Lower Lips- S line & 0 & $+3 \mathrm{~mm}$ & $+2 \mathrm{~mm}$ \\
\hline
\end{tabular}

\section{Treatment Planning}

Treatment goals were set based on the characteristics of the case and the desires of the patient in seeking orthodontic treatment. Since there was no significant skeletal compromise, the treatment goals were focused on reducing upper and lower incisor protrusion and reducing lip protrusion. Based from the clinical examination, diagnostic records, and cephalometric analysis, it was planned to relieve the maxillary and mandibular crowding with fixed appliance along with extraction of all first premolars. The treatment plan was suggested as follows: (1) extraction of the upper and lower first premolar teeth, (2) alignment of the upper and lower teeth with pre adjusted edgewise appliances, (3) retention with the upper and lower removable retainers. ${ }^{2}$ Based on OPG, 38 and 48 were not in good position, thus odontectomy for both teeth was performed before extraction of four premolars.

\section{Treatment progress}

After extraction of the four premolars, treatment was started with bonding of brackets and buccal tubes using 0.022 slots with preadjusted edgewise brackets, MBT. The patient was managed with the conventional anchorage system consisting of the Nance Appliance to limit the anchorage loss risk for upper jaw and double banded appliance for lower jaw (Figure 4). Levelling was done using Nickel-Titanium wire starting from size .012, $.014, .016$ until $.017 \times .025$. The retraction of the anterior segment begun with canine retraction first using Stainless Steel wire $.017 \times .025$ with omega stopper in mesial of $16,26,36$ and 46 and power chain. After canine retraction was done, anterior retraction was started using T-Loop in $.017 \times .0 .025$ stainless steel (Figure 4). After obtaining satisfactory overbite and overjet, class I molar and canine relationship had been attained. Almost one year and eight months later, all the fixed appliances were removed. Wrap around retainer was chosen for both arches.

\section{DISCUSSION}

The debate whether to extract or not has been occurring for many years but this was often linked to personal preferences rather than scientific criteria. Extraction of specific teeth is required in different types of malocclusions, and the decision to extract depends on the patient's medical history, the attitude to treatment, oral hygiene, caries rate, and the quality of teeth. ${ }^{6}$ Treatment of class I with crowding uses different modalities: interproximal reduction (stripping), expansion, derotation, uprighting, distalization, 

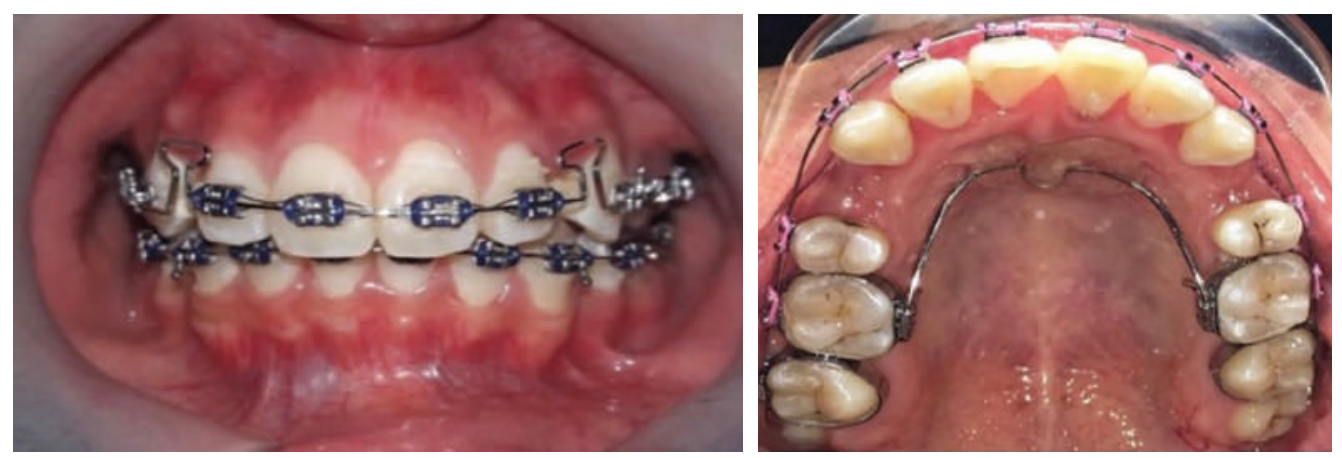

Figure 4. T-Loop and Nance Appliance During Treatment.
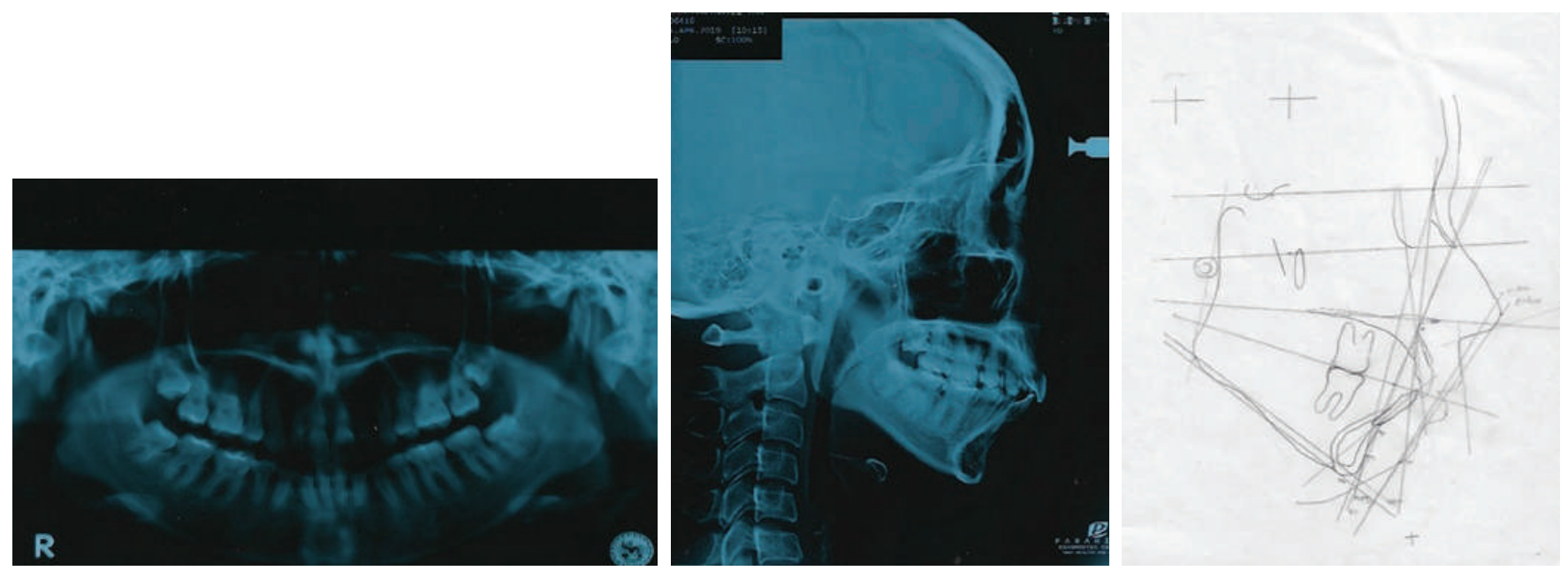

Figure 5. Post Treatment OPG and Cephalogram.

and extraction. Extraction of all first premolars is usually indicated in moderate to severe crowding in the labial segment to create space for relieving of crowding. It is the commonest pattern of extraction done by the orthodontist, as it is cantered between the anterior and posterior region of the jaw, and it provides good anchorage in the posterior region to retract the six anterior teeth. ${ }^{4}$ Persson et al. (1989) also examined the spontaneous long-term changes following premolar extractions alone, and found marked spontaneous arch alignment and residual space closure with age. ${ }^{7}$

One of the main reasons for choosing extraction or non-extraction is arch discrepancy. In this case, the patient had significant discrepancy, $10 \mathrm{~mm}$ for upper arch and 8 $\mathrm{mm}$ for upper arch. Based on Proffit et al., for $10 \mathrm{~mm}$ or more arch length discrepancy - extraction almost always is required to obtain enough space. ${ }^{8}$ Other indications for a first premolar extraction pattern instead of a second premolar extraction pattern include overbite, malocclusion type, and serial extraction therapy. Brandt and Safirstein stated that placing the extraction site closer to the anterior gives a mechanical advantage in leveling the arch as space is closed. This advantage is helpful when treating patients with a deep bite. ${ }^{9}$ Since this patient had several problems, extracting the four premolars was chosen as the treatment.
During space closure, controlling the overbite and posterior anchorage are a difficult biomechanical challenge. In extraction in deep overbite cases, leveling and alignment of the anterior teeth do not correct the deep overbite, and therefore, it must be corrected to ensure that full space closure is possible. ${ }^{10}$ The closing of extraction spaces can be performed using two main retraction techniques: en masse retraction (ER) or two-step retraction (TSR). For space closure achieved by ER, incisors and canines are retracted in just one step as if it were a single block. In TSR, the first step involves independently retracting the canines until they reach full contact with the second premolar; then they are incorporated into the posterior block of teeth composed of the second premolar and first and second molars. In the second step, this posterior block is used as an anchorage unit to retract the incisors. ${ }^{11}$ In this case, we were using Nance appliance and two-step retraction to lower risk of anchorage loss and we could see in the post treatment that there were no changes in MP-SN angles; the mandibule did not significant rotate posteriorly (Figures 5 and 6).

After the orthodontic treatment, Class I molar and canine relationships were achieved in both sides. Deep bite was corrected (Figure 7). The crowding was corrected in both dental arches. The inclinations of the upper and lower 
canines and midline deviation were corrected, resulting in a good inter incisal angle. Soft tissue profile of the patient was enhanced, thus satisfying one of the treatment goals (Figure 8).

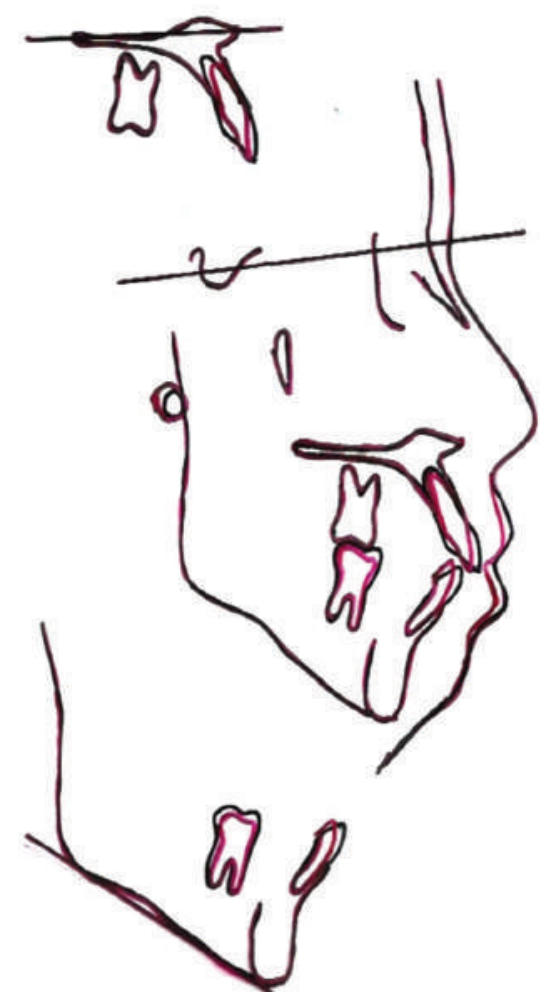

Figure 6. Superimposed Pre- and Post-Treatment.

\section{CONCLUSION}

Elimination of tooth tissue discrepancy by the extraction of first premolars is one of the options in the treatment of crowding. Treatment plan to extract or not to extract needs to be chosen based on many factors such as: discrepancy, profile, incisors inclination, and skeletal problem. Correct diagnosis is the key for success and stable orthodontic treatment results. Anchorage's problem should be considered with retraction to minimize anchorage loss. Orthodontic treatment goals could be achieved not only in the esthetic aspect but more importantly in the functional aspect.

\section{Acknowledgments}

We thank the patient and Airlangga University Dental Hospital for the consent to use the photographs and for the case to be presented.

\section{Statement of Authorship}

All authors participated in data collection and analysis, and approved the final version submitted.

\section{Author Disclosure}

All authors declared no conflict of interest.

\section{Funding Source \\ None.}
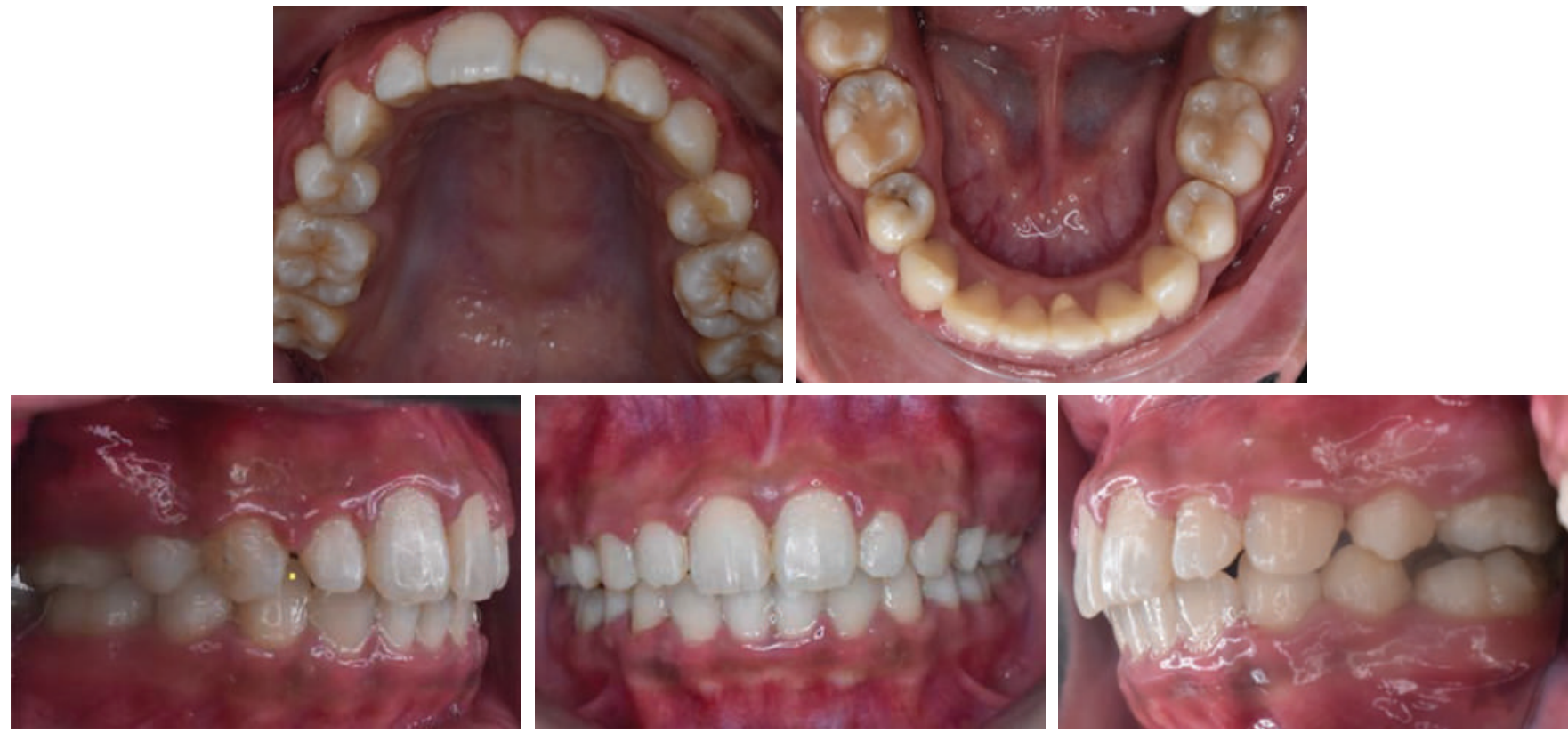

Figure 7. Intra Oral Photographs Post Treatment. 

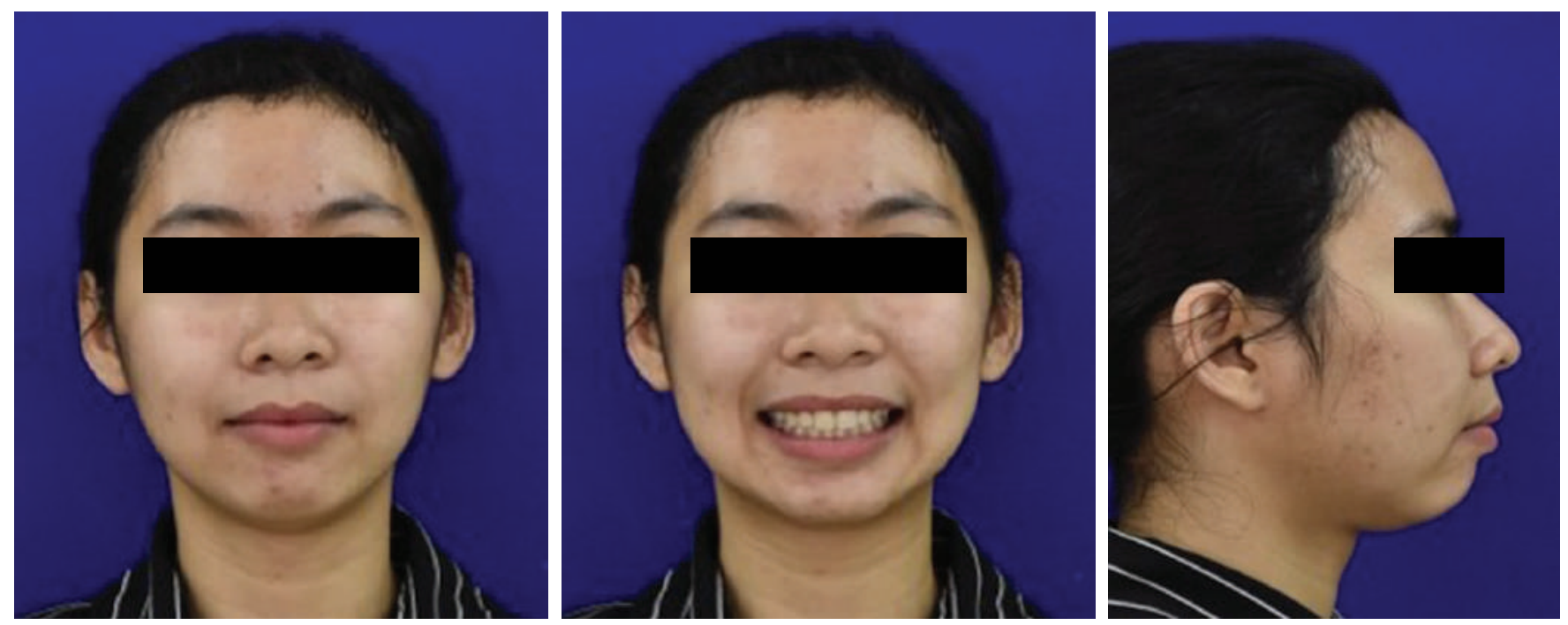

Figure 8. Extra Oral Photographs Post Treatment.

\section{REFERENCES}

1. Gudipaneni RK, Aldahmeshi RF, Patil SR, Alam MK. The prevalence of malocclusion and the need for orthodontic treatment among adolescents in the northern border region of Saudi Arabia: An epidemiological study. BMC Oral Health.2018 Feb; 18(1):16.

2. Alam MK, Nowrin SA, Shahid F, Haque S, Arshad A, Fareen N, et al. Treatment of Angle class I malocclusion with severe crowding by extraction of four premolars: A case report. Bangladesh Journal of Medical Science .2018 Sep; 17(4): 683-7.

3. Bills DA, Handelman CS, BeGole EA. Bimaxillary dentoalveolar protrusion: traits and orthodontic correction. Angle Orthod. 2005 May; 75(3):333-9.

4. Al-Ani MH, Mageet AO. Extraction Planning in Orthodontics. J Contemp Dent Pract. 2018; 19(5):623-7.

5. Ruellas ACO, Ruellas RMO, Romano FL, Pithon MM, Santos RL. Tooth extraction in orthodontics: an evaluation of diagnostic elements. Dental Press J Orthod. 2010 May-Jun; 15(3):134-57.
6. Travess H, Roberts-Harry D, Sandy J. Orthodontics. Part 8: Extractions in orthodontics. Br Dent J. 2004 Feb; 196(4):195-203.

7. Darendeliler N, Taner-sarisoy L. The influence of orthodontic extraction treatment on dental structures: a two-factor evaluation. Eur J Orthod. 2001 Jun; 23(3):295-303.

8. Khanum A, Prashantha GS, Mathew S, Naidu M, Kumar A. Extraction vs Non Extraction Controversy: A Review. J Dent Orofac Res. 2018; 14(1):41-8.

9. Turner RA. Quantitative Analysis of First- versus Second- Premolar Extraction Effects in Orthodontic Treatment. 2007. Thesis.

10. Wijaya H, Jenie I, Halim H. Biomechanics Strategies for Space Closure in Deep Overbite. J Dent Indones. 2012; 19(1):20-6.

11. Schneider PP, Gandini Júnior LG, Monini ADC, Pinto ADS, Kim KB. Comparison of anterior retraction and anchorage control between en masse retraction and two-step retraction: A randomized prospective clinical trial. Angle Orthod. 2019 Mar; 89(2):190-9. 